\title{
O papel do turismo cultural em Santiago (Cabo Verde): o caso do artesanato
}

\author{
Eduardo Moraes Sarmento* \\ Universidade Lusófona de Humanidades e Tecnologias (Portugal)
}

\begin{abstract}
Resumo: $\mathrm{O}$ artesanato é uma atividade que pode ser analisada nas suas dimensões histórica, económica, social, cultural e ambiental. Está ligada ao turismo, possuindo assim, grande potencial na geração de renda para a região que o desenvolve. Tendo em conta esse aspeto podemos dizer que é uma atividade que está em conformidade com as estratégias/alternativas para o desenvolvimento local. Com esse intuito, este artigo procura analisar o papel do turismo cultural na ilha de Santiago, tendo como o estudo de caso o artesanato. O objetivo principal é analisar como o turismo pode contribuir na preservação e valorização do artesanato da ilha de Santiago e também analisar a relação entre turismo, a cultura, e a contribuição da comunidade local na preservação do saber-fazer cultural tradicional da ilha. Foi utilizada uma análise qualitativa complementada por uma análise quantitativa a partir da recolha de 120 questionários aplicados aos cidadãos e artífices de Santiago.
\end{abstract}

Palavras-chave: Turismo cultural; Preservação Cultural; Artesanato; Cabo Verde.

\section{Cultural tourism role in Santiago (Cape Verde): handicraft case}

Abstract: Craft is an activity that can be analyzed in its historical, economic, social, cultural and environmental dimensions. It is connected to the tourist industry, thus having great potential in generating income for the region develops. Taking into account this aspect we can say that this is an activity in accordance with the strategies/alternatives for local development. To that end, this study seeks to examine the role of cultural tourism on the island of Santiago, taking as case study the craft. Therefore, the main objective is to analyze how tourism can contribute to the preservation and appreciation of the craft of the island of Santiago and also analyze the relationship between tourism and culture, and the contribution of the local community in the preservation of traditional cultural know-how the island. We used a qualitative analysis as a quantitative analysis. We applied 120 inquiries to the population of Santiago.

Keywords: Cultural Tourism; Cultural Preservation; Crafts; Cape Verde.

\section{Introdução}

Nas sociedades modernas, as transformações que o turismo tem sofrido tornaram-no numa fonte independente de crescimento e diversificação económica entre outros fatores (Okhrimenko, 2017; Ielenicz \& Simoni, 2013) o que é crucial pois nas últimas décadas muitos territórios que perderam ou viram reduzidas as suas principais atividades económicas têm centrado a sua atenção nos recursos turísticos e principalmente nos recursos culturais como forma de atingir novos patamares de desenvolvimento (Istoc, 2012). O turismo cultural tem sido unanimemente considerado como um dos tipos mais antigos de turismo e continua a representar uma orientação essencial para o desenvolvimento do turismo mundial (Richards \& Munsters, 2010), principalmente na Europa, onde o património cultural e natural são frequentemente considerados um pólo de atratividade do turismo (Băltescu, 2013). O turismo cultural tem representado mesmo até 40\% das viagens turísticas mundiais (Brida, Meleddu \& Paulina, 2013).

O século XXI levantou incertezas, choques, mas também um futuro promissor ao turismo (Butler, 2015).

* Universidade Lusófona de Humanidades e Tecnologias e CEsA (ISEG - Universidade de Lisboa; E-mail: emoraessarmento@ gmail.com 
Num mundo globalizado, os turistas estão cada vez mais exigentes e procuram destinos turísticos culturais que se adaptem às suas necessidades, aos seus desejos, às suas preferências, que permitam "conhecer coisas novas, aumentar os seus conhecimentos, observar os hábitos e costumes de outros povos e ainda satisfazer as suas necessidades espirituais" (Livramento, 2012: 29).

Neste contexto de mudança transformacional, o sistema económico é caracterizado pela globalização, urbanização, informatização entre outros fatores que exigem que outras atividades como o artesanato assumam maior preponderância na economia e na sociedade (Savushkin, 2014).

O estudo do desenvolvimento dos destinos turísticos centram a sua preocupação em diversos aspetos, destacando-se as dimensões sociais do destino, com os constructos de transformação e com os múltiplos produtos turísticos (McLennan et al., 2012), como acontece com a cultura e o artesanato.

Cabo Verde é tradicionalmente referenciado como uma pequena economia insular que tem apostado fortemente no turismo como forma de superar algumas das suas vulnerabilidades económicas e ambientais.

Cabo Verde é um arquipélago que tem enfrentado diversos desafios económicos e ambientais que têm condicionado a sua economia.

Apesar de Cabo verde ser considerado um destino turístico por excelência, um país de "morabeza", com uma vasta gama de oferta turística, só no período pós-independência este passou a ser considerado prioritário. Todavia, o turismo tem vindo a desenvolver-se ao longo dos anos de tal forma que a sua contribuição total para o PIB foi de CVE 76.0bn (USD782.9mn) representando $44.9 \%$ do PIB em 2017 e prevendo-se que cresça mais $3.1 \%$ em 2018, um aumento de $5.0 \%$ ao ano para CVE $127.8 \mathrm{bn}$ (USD1,316.1mn) ou seja 47.9\% do PIB em 2028 (WTTC, 2018).

Em termos de empregabilidade, em 2017, a contribuição total para o emprego representava $39.3 \%$ do emprego total, isto é cerca de 93,500 empregos. Estima-se que este valor suba 1.7\% in 2018 atingindo os 95,500 empregos e cresça $3.1 \%$ por ano o que significará 129,000 empregos em 2028 (45.7\% do total dos empregos) (WTTC, 2018).

No que se refere aos gastos dos turistas, Cabo Verde totalizou em 2017 CVE44.7bn esperando-se que elas cresçam 2,6\% em 2018 como resultado da captação de 634,000 turistas internacionais (WTTC, 2018).

De uma forma global estes dados servem para ver o potencial que o turismo pode desempenhar, caso o país tenha capacidade para aproveitar estes fluxos.

\section{Quadro 1: Evolução de estabelecimentos, capacidade e pessoal ao serviço em Cabo Verde, 2000 - 2017}

\begin{tabular}{|l|c|c|}
\hline Total Cabo Verde & $\mathbf{2 0 0 0}$ & $\mathbf{2 0 1 7}$ \\
\hline Estabelecimentos & 88 & 275 \\
\hline $\mathrm{N}^{\circ}$ de Quartos & 2391 & 12463 \\
\hline $\mathrm{N}^{\circ}$ de Camas & 4475 & 20421 \\
\hline Capacidade Alojamento & 5239 & 26987 \\
\hline Pessoal ao serviço & 1845 & 8825 \\
\hline Entradas & 145076 & 716775 \\
\hline Dormidas & 684733 & 4597477 \\
\hline Tx. Ocupaçâo Estab. Hotel. (\%) & 51,0 & 58,0 \\
\hline
\end{tabular}

Fonte: INE (2018)

Outros indicadores demonstram a evolução desta atividade neste país como é visível no quadro seguinte. 
Quadro 2: Estabelecimentos, capacidade e pessoal ao serviço em Cabo Verde por ilhas - 2017

\begin{tabular}{|l|c|c|c|c|c|c|c|c|c|}
\hline & $\begin{array}{c}\text { St. } \\
\text { Antão }\end{array}$ & $\begin{array}{c}\text { S. } \\
\text { Vicente }\end{array}$ & $\begin{array}{c}\text { S. } \\
\text { Nic. }\end{array}$ & Sal & Boavista & Maio & Santiago & Fogo & Brava \\
\cline { 2 - 11 } & $\mathbf{2 0 1 7}$ & $\mathbf{2 0 1 7}$ & $\mathbf{2 0 1 7}$ & $\mathbf{2 0 1 7}$ & $\mathbf{2 0 1 7}$ & $\mathbf{2 0 1 7}$ & $\mathbf{2 0 1 7}$ & $\mathbf{2 0 1 7}$ & $\mathbf{2 0 1 7}$ \\
\hline Estabelecimentos & 68 & 45 & 9 & 31 & 22 & 9 & 50 & 32 & 9 \\
\hline $\mathrm{N}^{\circ}$ de Quartos & 728 & 757 & 98 & 5996 & 3056 & 81 & 1303 & 356 & 88 \\
\hline $\mathrm{N}^{\circ}$ de Camas & 939 & 1133 & 134 & 9843 & 5629 & 113 & 2021 & 492 & 117 \\
\hline $\begin{array}{l}\text { Capacidade } \\
\text { Alojamento }\end{array}$ & 1396 & 1571 & 192 & 13 & 6531 & 176 & 2758 & 742 & 170 \\
\hline Pessoal ao serviço & 396 & 511 & 36 & 4936 & 1918 & 28 & 844 & 132 & 24 \\
\hline $\begin{array}{l}\text { Entradas } \\
\text { (milhares) }\end{array}$ & 26 & 45,5 & 1,8 & 343 & 206,6 & 1,7 & 78,4 & 11,9 & 1,6 \\
\hline $\begin{array}{l}\text { Dormidas } \\
\text { (milhares) }\end{array}$ & 72 & 132 & 7 & 1.656 & 2.518 & 8 & 163 & 31 & 9 \\
\hline $\begin{array}{l}\text { Tx. Ocupaçâo } \\
\text { Estab. Hotel. (\%) }\end{array}$ & 21,0 & 23 & 10 & 66 & 85 & 13 & 19 & 14 & 13 \\
\hline
\end{tabular}

Fonte: INE (2018)

Assim sendo, se atentarmos aos resultados obtidos, não é estranho que o fenómeno turístico se tenha tornado num importante instrumento para o desenvolvimento do país (WTTC, 2018). Mas não basta isso. É importante que o turismo se baseie em múltiplos fatores como acontece com a cultura e o artesanato.

Quer isto dizer que associar o turismo à cultura como fator indispensável para o desenvolvimento local é muito importante pois convém salientar que o turismo está intrinsecamente ligado às histórias e tradições culturais. O turismo pode auxiliar o progresso e benefícios de um determinado local/região. É cada vez mais notável a preocupação em realizar estudos em relação à cultura e a preservação dos valores como forma de preservar a identidade.

O turismo cultural no qual se integra o artesanato aparece como uma forma de valorizar, preservar e dar a conhecer às pessoas aquilo que é genuíno de um povo.

Sendo o artesanato a arte do saber-fazer de um povo e uma "importante forma de expressão cultural" (UNESCO, 2009: 21), ele deve ser cuidadosamente preservado e valorizado (Naidu, 2014).

Este artigo foca a sua análise no turismo cultural na ilha de Santiago tendo em atenção a situação do artesanato em três localidades rurais do interior da ilha de Santiago (Fonte Lima na Assomada; Calheta São Miguel e São Domingos). A escolha dessas áreas justifica-se pelo fato de serem as regiões onde estão situados os principais centros de artesanatos da ilha.

Mais concretamente, este estudo propõe alcançar dois objetivos específicos: (i) analisar a importância do artesanato como produto turístico cultural; (ii) identificar a sua contribuição para o bem-estar da comunidade no âmbito do turismo.

Metodologicamente, foram aplicadas duas técnicas: a técnica da entrevista semiestruturada direcionada aos artesãos da ilha de modo a compreender a atividade desenvolvida por eles e a aplicação de inquéritos a 120 santiaguenses. Esta análise foi complementada com a presença nas três regiões em estudo.

Em termos de estrutura, o artigo está organizado em 3 secções, a saber: (i) revisão da literatura; (ii) caracterização do artesanato e (iii) metodologia e estudo de caso. Finalmente, encontramos as principais conclusões. 


\section{Revisão da literatura}

O turismo cultural começou a ser reconhecido como um produto turístico sobretudo a partir dos finais dos anos 70. Uma das principais causas do crescimento do turismo cultural nas últimas décadas deve-se ao crescimento dos níveis de educação, à informação que os turistas têm e ao nível de exigência (Dias, 2010).

No primeiro período dos anos 90, a maioria dos estudos sobre turismo cultural destacava as ligações entre o turismo e o património cultural, defendendo a ideia de que o património é a força motriz do desenvolvimento das atividades turísticas (Baltescu \& Boscor, 2013). Embora o turismo cultural fosse visto como uma forma de visitar atrações culturais localizadas em áreas urbanas e rurais (Richards, 2011), com o passar do tempo, surgiu uma visão mais ampla da relação cultura - turismo, que integrou artes, artesanato, eventos culturais, arquitetura e design e, mais recentemente, atividades criativas (Munsters, 2007).

Embora haja múltiplos impactos do turismo cultural que podem ser tanto positivos quanto negativos (Raabova, Merta \& Ticha, 2013), estimar os seus impactos económicos é bastante difícil porque não há informação suficiente (Breda, Meleddu \& Paulina, 2013).

A literatura especializada tem destacado os aspectos qualitativos da experiência de viagem dos visitantes e das comunidades dos locais visitados (Richards \& Munsters, 2010), bem como a genuinidade dos elementos que reforçam a experiência de viagem (Kim \& Jamal, 2007; Belhassen et al, 2008; Zhu, 2012) ou a melhor utilização de recursos culturais como elemento de desenvolvimento de experiências de viagem (Richards, 2011) baseadas no conhecimento explorando a história, a singularidade e a identidade dos locais, descobrindo o que torna um evento ou um destino único, pressupondo uma descoberta pessoal por via das artes e das humanidades (Pérez, 2009).

Outros autores reforçaram a influência do desenvolvimento do turismo cultural na melhoria dos efeitos negativos da sazonalidade (Figini \& Vici, 2012), enquanto outros enfatizaram a importância da interconexão entre turismo cultural e criatividade, a fim de permitir que o consumidor compreenda melhor as características particulares, a complexidade e a identidade dos lugares visitados (Frey \& Pamini, 2009) e aprenda sobre o passado de uma região ou um país, de uma maneira divertida e informativa (Pérez, 2009).

A criatividade pode ser considerada como uma forma de envolver os turistas nas atividades cotidianas e estimular o consumo aos elementos do património com baixo grau de tangibilidade (Richards, 2011) e, portanto, pode criar efeitos positivos no aumento da renda da população local e na sua participação direta no aumento da atratividade do turismo local (Fillis, 2009).

Temos testemunhado um desenvolvimento espetacular na oferta de produtos e serviços, levando em conta as exigências do cliente (Madar et al, 2006) e seu comportamento de compra relativamente às lembranças feitas por artesãos locais e, portanto, do artesanato (Hu \& Yu, 2007; Lynch et al., 2011).

Diversos pesquisadores têm mostrado a importância da valorização do património e do turismo cultural como forma de garantir a competitividade local (Bandarin et al, 2011; Emekli \& Baykal, 2011; Boix et al, 2012; Korunovski \& Marinoski, 2012). Para se alcançar uma competitividade adequada do turismo cultural, será necessário conseguir uma colaboração eficiente entre as estratégias de todos os atores envolvidos (Alberti \& Giusti, 2012). Nos casos em que houve iniciativa e colaboração, os resultados a nível local / regional foram notáveis (Iorio \& Wall, 2012), uma vez que o turismo pode ser usado como uma ferramenta para aumentar o padrão de vida, especialmente nas áreas rurais (Zeng \& Ryan , 2012; Mbaiwa, 2011; Lee et al, 2013).

Sendo o turismo um fenómeno social, nota-se actualmente uma maior preocupação sobre a preservação cultural de forma sustentada. Neste sentido, a comunidade local deve ser a primeira a conhecer bem a sua história, a valorizar a sua cultura como forma de preservar a sua identidade cultural (Panasiuk, 2013).

É importante destacar que o turismo cultural necessita de estar em sintonia com a comunidade local, não apenas pela possibilidade do desenvolvimento local, mas também pelo desenvolvimento do espírito comunitário (sentimento de pertença) e a melhoria na qualidade de vida da população que esta atividade lhes proporciona (Costa, 2011).

É importante que a comunidade tenha a noção do valor e dos significados da sua cultura promovendo assim uma relação de respeito e ter uma atitude consciente de conservação por parte daqueles que que de algum modo se interessam pelas artes e ofícios tradicionais (Monteiro, 2006).

A participação da comunidade local no processo da preservação é essencial, pois a comunidade local é quem melhor conhece a realidade, a vivência do local e torna mais fácil de desenvolver ideias, identificar os problemas e estratégias para a valorização e preservação para o bem-estar social. Por 
outras palavras, são os artesãos que asseguram a continuidade das tradições culturais, transmitindo nos seus estilos e formas a identidade local e possibilitando ainda aos turistas a ligação e vivência com o passado (Costa, 2011).

Envolver a comunidade para que ela participe no processo, possibilita-lhes o (re) descobrir de novas formas de olhar e apreciar o lugar onde vivem. Isto leva a que eles se orgulhem do que é deles, tornando um elo importante na interação com os potenciais visitantes (Carvalho, 2008).

No entanto, pode haver um lado negativo como consequência da presença de um maior número de turistas que pode afetar negativamente não apenas o meio ambiente, mas também a coesão social local (Girard \& Nijkamp, 2009) ou os princípios do desenvolvimento sustentável (Tao \& Wall, 2009; Fatemeh et al, 2015).

O património turístico cultural pode ser identificado por meio de alguns valores específicos: valor estético, espiritual, social, histórico, simbólico e genuíno (Girard \& Nijkamp, 2009). Os seus recursos possuem características específicas de renovabilidade (Ning \& Hoon, 2011) que poderão solucionar conflitos sociais locais (Yang et al, 2013). Portanto, é necessário utilizar os indicadores de desenvolvimento sustentável na gestão de destinos turísticos culturais (Lazano-Oyola et al, 2012), a fim de orientar os visitantes para o consumo turístico (Olsen, 2003).

Enquanto os turistas realizam as suas atividades culturais eles procuram experiências autênticas, que incluem o sentimento de "auto-revelação", o sentimento de "ser fiel a si mesmo" e o sentimento de "vida real" que é uma consequência da interação com a população local (Cohen, Oslen \& Pearce 2012).

\section{Artesanato}

\section{Conceito de artesanato}

$\mathrm{O}$ artesanato ao representar o modo de vida de uma determinada comunidade, é um bem cultural que deve ser preservado e transmitido às novas gerações (Monteiro, 2006, Sarmento, 2008) já que "o artesanato significa um fazer ou o objecto que tem por origem o facto de ser eminente manual. Isto é, são as mãos que executam o trabalho" (Freeman, 2010: 25) e em última instância representa o modo de vida de uma determinada sociedade.

\section{A Relação entre o artesanato e turismo}

Para Costa (2011: 16) "o turismo influencia o desenvolvimento do artesanato local, através dos turistas que procuram artigos de significado cultural ou religioso que sejam autênticos, o que incrementa a economia local, possibilitando a distribuição de benefícios diretos para os residentes".

$\mathrm{O}$ artesanato representa a memória de uma dada comunidade e contribui para o desenvolvimento sustentável da comunidade potenciando o desenvolvimento do turismo cultural de uma determinada região turística. Desta forma, a heterogeneidade e o dinamismo aparecem como fatores influenciadores do ambiente interno (Jakulin, 2016).

No entanto, para que o artesanato sirva de meio de desenvolvimento turístico é necessário que tenha caraterísticas culturais desse local ou região tornando-o numa atração ou produto turístico.

Com o passar do tempo o artesanato deve evoluir de forma a acompanhar as necessidades do consumidor; inovar o que é tradicional sem perder a identidade da cultura local.

Cada região produz peças artesanais que lhe configuram como peças únicas/exclusivas, que difere das de outras regiões.

\section{Metodologia e estudo de caso}

Em termos de amostra, foram aplicados inquéritos de forma aleatória a 120 habitantes da ilha de Santiago incluindo os artesãos durante os meses de Fevereiro e Março de 2013.

Foi inicialmente realizada uma entrevista semiestruturada de modo a obter o máximo de informação sobre o assunto em estudo. Foi feito um pré-teste tendo sido corrigido questões pontuais.

Recolheram-se 150 inquéritos, mas 30 apresentavam problemas, tendo sido eliminados do estudo.

Também se fez trabalho de campo diretamente junto dos artesãos, tendo-se recolhido informação útil e complementar a esta análise. 


\subsection{Análise do trabalho de campo}

Historicamente o artesanato cabo-verdiano surgiu das influências dos povos africanos e dos portugueses. Destaca-se no caso de Santiago a tecelagem ("panu-di- terra" em algodão no tear rudimentar), a cestaria e a esteiraria feitos com caniço e a cerâmica fabricado em peças em barro vermelho. Além disso, encontramos os acessórios como "chapéu-di-palha", brincos e colares confecionados com cascas de coco e conchas dos mares

$\mathrm{O}$ artesanato tem sido um elemento cultural de grande importância que utiliza as matérias-primas disponíveis na ilha.

O estudo focou-se em três áreas: Fonte Lima (Assomada); São Miguel (Calheta São Miguel) e São Domingos, todas pequenas comunidades do interior da ilha de Santiago.

\section{Fonte Lima - Assomada}

Esta pequena comunidade localiza-se próximo da Assomada, situada no centro da ilha. O artesanato da região é a olaria (cerâmica), tradição antiga quanto à história da descoberta e do povoamento das ilhas. $\mathrm{O}$ artesanato foi introduzido na ilha com a chegada dos primeiros habitantes (africanos e portugueses), o que justifica as semelhanças das peças artesanais originárias desses povos.

Tem sido uma atividade que manteve até aos dias de hoje a técnica da sua confeção manual que pouco nada se alterou na maneira de os fazer (escolha, preparação e cozedura do barro).

A cerâmica sempre foi uma importante fonte de rendimento familiar e complementar à agropecuária. Ambas as atividades são sazonais. O fator climático é o grande responsável por esses condicionalismos, pois como se sabe nas épocas das chuvas (entre Junho e Novembro) a agricultura torna-se a atividade principal. Porém, a apanha do barro também nessa época é condicionada pelo fato do local de apanha se situar nos campos de cultivo.

A cerâmica da região é considerada como um produto de grande valor cultural e económico.

\section{Calheta São Miguel}

Situa-se na região nordeste da ilha, a $42 \mathrm{~km}$ da capital e muito próximo da cidade da Assomada. A economia local é semelhante às demais regiões do interior da ilha, assentando essencialmente na agricultura, criação de gado e pesca. O "panu-di-terra", a fabricação da cestaria e a esteiraria são atividades que têm contribuído para o sucesso da economia local.

\section{São Domingos}

São Domingos situa-se a sudoeste da ilha, entre os concelhos da Praia e de São Lourenço dos Orgãos. É um concelho rural onde a principal atividade da população é a agropecuária.

A produção artesanal de São Domingos é que mais tem inovado ao longo dos últimos anos é a olaria, e o "panu-di-terra".

Concluindo, estas regiões continuaram a executar esta arte do saber-fazer de forma muito tradicional, tal como lhes foi passado pelos seus antecessores. A técnica simples e primitiva da moldagem ou do tecer usada manualmente mantém-se até os dias de hoje, a tendência permite a conservação dessa mesma técnica.

Apesar das dificuldades que o artesanato tem vindo a passar nos últimos anos, os artesãos continuam a dedicar-se a esta arte de forma a manter a tradição, a ocupar os tempos livres e até mesmo como meio de subsistência, muito embora a venda do artesanato já não seja suficiente para garantir a subsistência.

Esta atividade é explorada na sua maioria por mão-de-obra familiar e quando é necessário produzir peças artesanais em grandes quantidades recorrem ao sistema típico de "djuntamô".

$\mathrm{Da}$ análise presencial aos locais selecionados e das conversas com vários artesãos, constataram-se alguns pontos fortes e fracos.

Relativamente aos pontos fortes: (i) adaptação do artesanato às novas exigências dos consumidores como por exemplo através das novas peças miniaturas; (ii) a representação adequada da cultura local e identidade do povo refletindo uma cultura baseada em saberes tradicionais que remontam aos antepassados; (iii) baseia-se em produtos ecológicos; (iv) contribui para o desenvolvimento local e potencia uma oportunidade para se aumentar os rendimentos familiares; (v) promove o turismo cultural; (vi) cria peças únicas com caraterísticas locais (peças com história); (vii) a criação de um selo de certificação do artesanato feito no país ("created in Cabo Verde") pelo Ministério da Cultura e a Direção Nacional de Artesanato (MCDNA); (viii) existência de algumas feiras nacionais e internacionais que são fundamentais na medida em que sendo o artesanato um produto pouco lucrativo para o artesão, muitas vezes não 
lhe permite ter uma loja própria porque o arrendamento dos espaços para loja normalmente são de custos elevados o que não lhe trará grandes vantagens; (ix) o artesanato tem sido um potenciador do desenvolvimento local na medida em que não requer um investimento muito elevado uma vez que as regiões normalmente possuem as matérias-primas necessárias à sua produção; (x) o artesanato é geralmente desenvolvido no seio familiar e frequentemente através do sistema "djunta mô", um sistema de apoio mútuo. Antigamente eram as mulheres que trabalhavam nesta arte desde o processo inicial até ao consumidor final. Agora a situação é inversa.

É fundamental manter a fidelidade das tradições (neste caso a produção artesanal) do local de origem e por outro lado evitar a produção em massa que poderia conduzir ao seu empobrecimento (UNESCO, 2009).

Finalmente, tem sido desenvolvido o processo empreendedor e inovativo em termos de processo produtivo, da difusão e comercialização do artesanato. Já existem atualmente alguns artesãos a explorar a utilidade do barro e reintroduzir o barro no quotidiano cabo-verdiano. No caso do barro/cerâmica em particular podemos destacar as seguintes inovações: implementação de utensílios como prato, copo, jarro em restaurantes; criação de tijolos decorativos ${ }^{1}$; pintura com barro considerando ser um produto ecológico.

O empreendedorismo e a inovação também funcionam como incentivo aos artesãos no desenvolvimento do artesanato local, aumentando-lhes as oportunidades, melhorando as condições de vida e resgatando o saber fazer tradicional. A principal preocupação é evitar a descaraterização do artesanato tradicional.

Em contrapartida, existem algumas limitações: (i) demora na produção da peça; (ii) escassa procura turística por falta de locais de venda; (iii) falta de apoio por parte das entidades governativas; (iv) sazonalidade das matérias primas; (v) perda de identidade devido à chegada de artesãos da Costa Africana, que vendem as suas peças (animais selvagens como elefantes, rinocerontes, girafas entre outros, e que não existem em Cabo Verde); (vi) falta de fiscalização e de certificação dos produtos que garantam a autenticidade de mesmo; (vii) a necessidade de se criar um sistema de transmissão do conhecimento às gerações mais novas evitando o fim desta atividade.

\subsection{Análise dos inquéritos}

A maioria dos inquiridos nacionais são da Assomada (31 -25,8\%), seguindo-se os da Calheta São Miguel (21 - 17,5\%) e Fonte de Lima (19 - 15,8\%).

\section{Quadro 3: Zona de recolha dos dados}

\begin{tabular}{|l|c|c|}
\hline & Frequência & Percentagem \\
\hline Assomada & 31 & 25,8 \\
\hline Calheta-São Miguel & 21 & 17,5 \\
\hline Cidade Velha & 7 & 5,8 \\
\hline Fonte Lima & 19 & 15,8 \\
\hline Pico & 8 & 6,7 \\
\hline Praia & 9 & 7,5 \\
\hline São Domingos & 14 & 11,7 \\
\hline São Laurenço dos Orgãos & 3 & 2,5 \\
\hline Serra Malagueta & 2 & 1,7 \\
\hline Tarrafal & 6 & 5,0 \\
\hline Total & 120 & 100,0 \\
\hline
\end{tabular}

Fonte: Os autores

Por género, os inquiridos masculinos representam pouco mais de metade $(55,0 \%, \mathrm{n}=66)$ enquanto os inquiridos femininos representam $45,0 \%(n=54)$ do total de respostas. Em termos de escalões etários, é importante destacar que os inquiridos da faixa etária dos 20-25 anos, são os que predominam com $25,8 \%$. Os mais novos representam $11,7 \%$ e os mais velhos $5,8 \%$ dos inquiridos respetivamente. 


\section{Gráfico 1: Escalões etários}

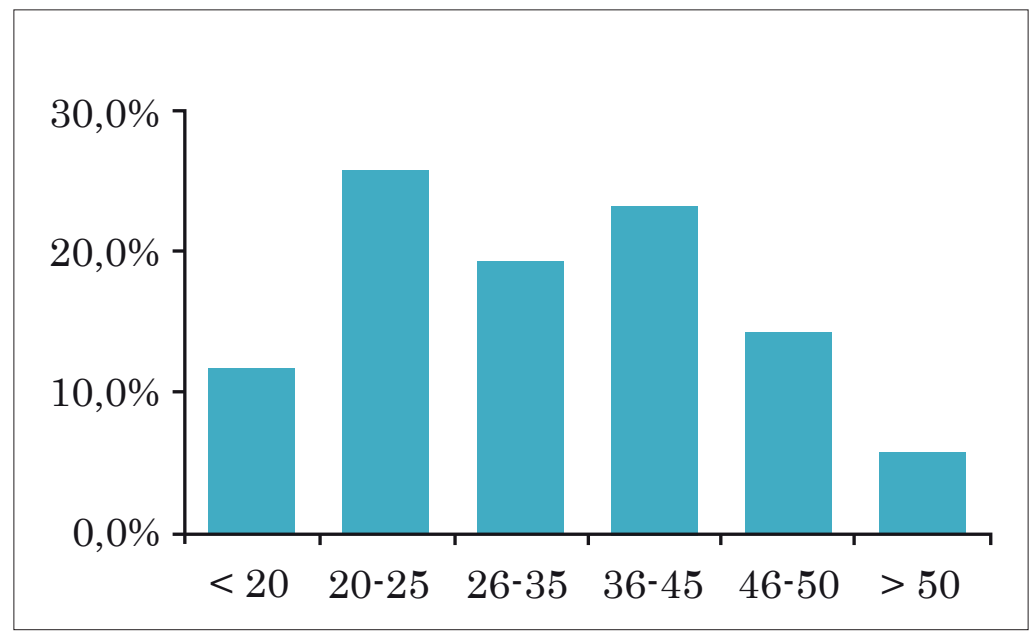

Fonte: Os autores

Em termos de estado civil, $53 \%$ são solteiros, $43 \%$ casados, $1 \%$ divorciados e $3 \%$ viúvos.

Relativamente à escolaridade, $29 \%$ têm o $12^{\circ}$ ano, $27 \%$ o $9^{\circ}$ ano e $15 \%$ não têm habilitações literárias. Os inquiridos com o ensino superior representam $16 \%$. 13\% têm a $4^{\mathrm{a}}$ classe.

A parte II do inquérito integra as questões relacionadas com o conhecimento e preservação/valorização do artesanato.

119 das pessoas $(99,2 \%)$ inquiridas referiram ter conhecimento dos vários tipos de artesanato da ilha enquanto 118 (98,3\%) afirmam que conhecem as suas histórias. Relativamente ao número de peças artesanais que possuem em média, as pessoas afirmam que têm 6 peças de artesanato da ilha em casa.

Quanto à compra e interesse do artesanato dos locais que visitam cerca de $(29,2 \%$ - 35) dos inquiridos respondem que compram peças dos locais que visitam, 62,5 (75) compram às vezes caso se interessem e apenas $8,3 \%$ (10) afirma que nunca compra artesanato.

Em termos de divulgação do artesanato, 69 pessoas (57,5\%) preferem as feiras, $24,2 \%$ os sítios de atracões turísticas, $13,3 \%$ defendem a organização de feiras e workshops e finalmente surgem os locais históricos (5\%).

Quanto à preservação do artesanato, 34,2\% salientaram ser importante e $65,8 \%$ consideram ser muito importante.

$56,7 \%$ (68) dos inquiridos consideram que as entidades responsáveis poderiam fazer mais em prol da preservação dos produtos artesanais da ilha enquanto $2,5 \%$ (3) afirmam que nada é feito. 26 pessoas $(21,7 \%)$ entende que os responsáveis estão preocupados com esta atividade e $23(19,2 \%)$ dizem que muito pouco tem sido feito.

Metade da amostra considera que os produtos de artesanato deveriam ter mais exposições enquanto a outra metade indica que deveriam ser expostos com mais frequência.

Tendo em atenção os preços praticados, $66,7 \%$ dos inquiridos afirmam que são bons, 18,3 baixos e os restantes acessíveis.

Quanto à divulgação do artesanato, os inquiridos dão como sugestão de que se deveria divulgar mais em feiras $(55,8 \%)$, sítios históricos $(11,7 \%)$ e eventos culturais ou sítios com maior afluência turística $(10,0 \%)$.

Na parte III do inquérito, faz-se uma análise das questões relacionadas com a avaliação do turismo na ilha de Santiago. Curiosamente, apesar do crescente número de turistas, mais de metade da amostra considera como insuficiente o número de turistas que visitam a ilha (68\%) e $32 \%$ considera-o como adequado.

A opinião que os inquiridos têm sobre a ilha é unanimemente positiva. 
Por último, os inquiridos dividem-se sobre o que pensam do acesso à informação das decisões políticas relacionadas com o turismo já que $35,8 \%$ consideram que sim, $36,7 \%$ consideram que não e os restantes $27,5 \%$ mais ou menos.

A tendência de compra de artesanato por género é mais elevada nos homens do que nas mulheres (30,3\% vs $27,8 \%)$, embora a diferença não seja estatisticamente significativa, $\chi^{2}(2)=0,169, p=, 919$.

Quadro 4: Compra de artesanato por género

\begin{tabular}{|c|c|c|c|c|c|}
\hline \multirow{2}{*}{\multicolumn{2}{|c|}{ Género }} & \multicolumn{3}{|c|}{ Compra artesanato } & \multirow{3}{*}{$\begin{array}{c}\text { Total } \\
\\
54\end{array}$} \\
\hline & & \multirow{2}{*}{$\begin{array}{c}\text { Compro } \\
\text { sempre }\end{array}$} & \multirow{2}{*}{$\begin{array}{c}\begin{array}{c}\text { Nunca } \\
\text { compro }\end{array} \\
5 \\
\end{array}$} & \multirow{2}{*}{$\begin{array}{c}\text { As vezes se me } \\
\text { interessar } \\
34 \\
\end{array}$} & \\
\hline \multirow{4}{*}{ Feminino } & Frequência & & & & \\
\hline & $\%$ sexo & $27,8 \%$ & $9,3 \%$ & $63,0 \%$ & $100,0 \%$ \\
\hline & $\%$ compra & $42,9 \%$ & $50,0 \%$ & $45,3 \%$ & $45,0 \%$ \\
\hline & $\%$ do total & $12,5 \%$ & $4,2 \%$ & $28,3 \%$ & $45,0 \%$ \\
\hline \multirow{4}{*}{ Masculino } & Frequência & 20 & 5 & 41 & 66 \\
\hline & $\%$ sexo & $30,3 \%$ & $7,6 \%$ & $62,1 \%$ & $100,0 \%$ \\
\hline & $\%$ compra & $57,1 \%$ & $50,0 \%$ & $54,7 \%$ & $55,0 \%$ \\
\hline & $\%$ do total & $16,7 \%$ & $4,2 \%$ & $34,2 \%$ & $55,0 \%$ \\
\hline \multirow{4}{*}{ Total } & Frequência & 35 & 10 & 75 & 120 \\
\hline & $\%$ sexo & $29,2 \%$ & $8,3 \%$ & $62,5 \%$ & $100,0 \%$ \\
\hline & \% compra & $100,0 \%$ & $100,0 \%$ & $100,0 \%$ & $100,0 \%$ \\
\hline & $\%$ do total & $29,2 \%$ & $8,3 \%$ & $62,5 \%$ & $100,0 \%$ \\
\hline
\end{tabular}

Fonte: Os autores

A compra de artesanato por escalão etário mostra que há uma proporção significativamente mais elevada no escalão dos mais jovens que afirmam nunca comprar artesanato $(35,7 \%), \chi 2(10)=22,757, p=, 012$. 


\section{Quadro 5: Compra de artesanato por idade}

\begin{tabular}{|c|c|c|c|c|c|}
\hline \multirow{2}{*}{ Idade } & & \multicolumn{3}{|c|}{ Compra de artesanato } & \multirow{3}{*}{$\begin{array}{c}\text { Total } \\
14\end{array}$} \\
\hline & & \multirow{2}{*}{$\begin{array}{c}\text { Compro } \\
\text { sempre }\end{array}$} & \multirow{2}{*}{$\begin{array}{c}\begin{array}{c}\text { Nunca } \\
\text { compro }\end{array} \\
5 \\
\end{array}$} & \multirow{2}{*}{$\begin{array}{c}\begin{array}{c}\text { Às vezes } \\
\text { se me }\end{array} \\
\text { interessar } \\
8\end{array}$} & \\
\hline \multirow{4}{*}{$<20$} & Frequência & & & & \\
\hline & $\%$ idade & $7,1 \%$ & $35,7 \%$ & $57,1 \%$ & $100,0 \%$ \\
\hline & $\%$ compra & $2,9 \%$ & $50,0 \%$ & $10,7 \%$ & $11,7 \%$ \\
\hline & $\%$ total & $0,8 \%$ & $4,2 \%$ & $6,7 \%$ & $11,7 \%$ \\
\hline \multirow{4}{*}{$20-25$} & Frequência & 7 & 2 & 22 & 31 \\
\hline & $\%$ idade & $22,6 \%$ & $6,5 \%$ & $71,0 \%$ & $100,0 \%$ \\
\hline & $\%$ compra & $20,0 \%$ & $20,0 \%$ & $29,3 \%$ & $25,8 \%$ \\
\hline & $\%$ total & $5,8 \%$ & $1,7 \%$ & $18,3 \%$ & $25,8 \%$ \\
\hline \multirow{4}{*}{$26-35$} & Frequência & 8 & 2 & 13 & 23 \\
\hline & $\%$ idade & $34,8 \%$ & $8,7 \%$ & $56,5 \%$ & $100,0 \%$ \\
\hline & $\%$ compra & $22,9 \%$ & $20,0 \%$ & $17,3 \%$ & $19,2 \%$ \\
\hline & $\%$ total & $6,7 \%$ & $1,7 \%$ & $10,8 \%$ & $19,2 \%$ \\
\hline \multirow{4}{*}{$36-45$} & Frequência & 10 & 1 & 17 & 28 \\
\hline & $\%$ idade & $35,7 \%$ & $3,6 \%$ & $60,7 \%$ & $100,0 \%$ \\
\hline & $\%$ compra & $28,6 \%$ & $10,0 \%$ & $22,7 \%$ & $23,3 \%$ \\
\hline & $\%$ total & $8,3 \%$ & $0,8 \%$ & $14,2 \%$ & $23,3 \%$ \\
\hline \multirow{4}{*}{$46-50$} & Frequência & 8 & 0 & 9 & 17 \\
\hline & $\%$ idade & $47,1 \%$ & $0,0 \%$ & $52,9 \%$ & $100,0 \%$ \\
\hline & \% compra & $22,9 \%$ & $0,0 \%$ & $12,0 \%$ & $14,2 \%$ \\
\hline & $\%$ total & $6,7 \%$ & $0,0 \%$ & $7,5 \%$ & $14,2 \%$ \\
\hline \multirow{4}{*}{$>50$} & Frequência & 1 & 0 & 6 & 7 \\
\hline & $\%$ idade & $14,3 \%$ & $0,0 \%$ & $85,7 \%$ & $100,0 \%$ \\
\hline & \% compra & $2,9 \%$ & $0,0 \%$ & $8,0 \%$ & $5,8 \%$ \\
\hline & $\%$ total & $0,8 \%$ & $0,0 \%$ & $5,0 \%$ & $5,8 \%$ \\
\hline \multirow{4}{*}{ Total } & Frequência & 35 & 10 & 75 & 120 \\
\hline & $\%$ idade & $29,2 \%$ & $8,3 \%$ & $62,5 \%$ & $100,0 \%$ \\
\hline & \% compra & $100,0 \%$ & $100,0 \%$ & $100,0 \%$ & $100,0 \%$ \\
\hline & $\%$ total & $29,2 \%$ & $8,3 \%$ & $62,5 \%$ & $100,0 \%$ \\
\hline
\end{tabular}

Fonte: Os autores

A importância atribuída à preservação do artesanato é semelhante em homens e mulheres, teste de exato de Fisher, $p=, 567$. 
Tabela 27: Importância atribuída ao artesanato e género

\begin{tabular}{|c|c|c|c|c|}
\hline \multirow{2}{*}{\multicolumn{2}{|c|}{ Sexo }} & \multicolumn{2}{|c|}{ Importância } & \multirow{3}{*}{$\begin{array}{c}\text { Total } \\
54\end{array}$} \\
\hline & & \multirow{2}{*}{$\begin{array}{c}\text { Importante } \\
20\end{array}$} & \multirow{2}{*}{$\begin{array}{c}\begin{array}{c}\text { Muito } \\
\text { importante }\end{array} \\
34\end{array}$} & \\
\hline \multirow{4}{*}{ Feminino } & Frequência & & & \\
\hline & $\%$ sexo & $37,0 \%$ & $63,0 \%$ & $100,0 \%$ \\
\hline & \% Importância & $48,8 \%$ & $43,0 \%$ & $45,0 \%$ \\
\hline & $\%$ do total & $16,7 \%$ & $28,3 \%$ & $45,0 \%$ \\
\hline \multirow{4}{*}{ Masculino } & Frequência & 21 & 45 & 66 \\
\hline & $\%$ sexo & $31,8 \%$ & $68,2 \%$ & $100,0 \%$ \\
\hline & \% Importância & $51,2 \%$ & $57,0 \%$ & $55,0 \%$ \\
\hline & $\%$ do total & $17,5 \%$ & $37,5 \%$ & $55,0 \%$ \\
\hline \multirow{4}{*}{ Total } & Frequência & 41 & 79 & 120 \\
\hline & $\%$ sexo & $34,2 \%$ & $65,8 \%$ & $100,0 \%$ \\
\hline & \% Importância & $100,0 \%$ & $100,0 \%$ & $100,0 \%$ \\
\hline & $\%$ do total & $34,2 \%$ & $65,8 \%$ & $100,0 \%$ \\
\hline
\end{tabular}

Fonte: Os autores

Gráfico 8: Importância atribuída ao artesanato e género

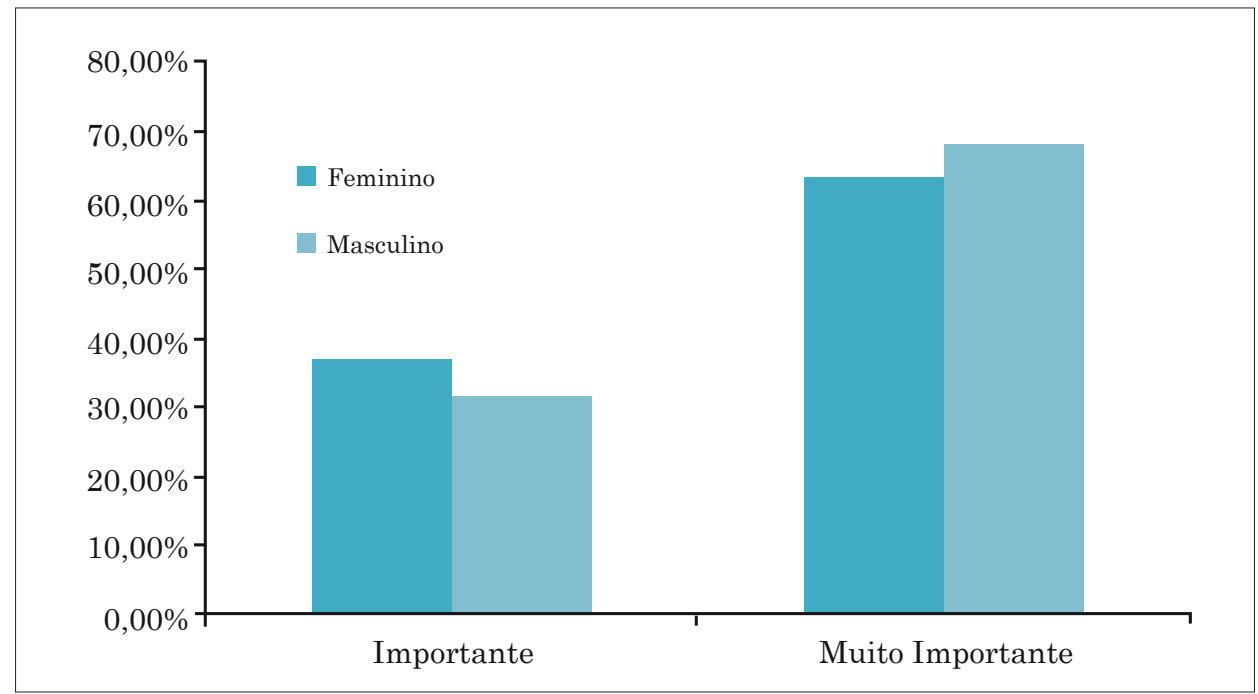

Fonte: Inquéritos, SPSS

A importância atribuída à preservação do artesanato é semelhante nas faixas etárias, $\chi^{2}(5)=1,474$, $p=, 916$. 
Tabela 29: Preservação do artesanato

\begin{tabular}{|c|c|c|c|c|}
\hline \multirow{2}{*}{\multicolumn{2}{|c|}{ Idade }} & \multicolumn{2}{|c|}{ Importância } & \multirow{3}{*}{$\begin{array}{c}\text { Total } \\
14 \\
\end{array}$} \\
\hline & & \multirow{2}{*}{$\frac{\text { Importante }}{6}$} & \multirow{2}{*}{$\begin{array}{c}\text { Muito importante } \\
8\end{array}$} & \\
\hline \multirow{4}{*}{$<20$} & Frequência & & & \\
\hline & $\%$ sexo & $42,9 \%$ & $57,1 \%$ & $100,0 \%$ \\
\hline & \% Importância & $14,6 \%$ & $10,1 \%$ & $11,7 \%$ \\
\hline & $\%$ do total & $5,0 \%$ & $6,7 \%$ & $11,7 \%$ \\
\hline \multirow{4}{*}{$20-25$} & Frequência & 9 & 22 & 31 \\
\hline & $\%$ sexo & $29,0 \%$ & $71,0 \%$ & $100,0 \%$ \\
\hline & \% Importância & $22,0 \%$ & $27,8 \%$ & $25,8 \%$ \\
\hline & $\%$ do total & $7,5 \%$ & $18,3 \%$ & $25,8 \%$ \\
\hline \multirow{4}{*}{$26-35$} & Frequência & 7 & 16 & 23 \\
\hline & $\%$ sexo & $30,4 \%$ & $69,6 \%$ & $100,0 \%$ \\
\hline & \% Importância & $17,1 \%$ & $20,3 \%$ & $19,2 \%$ \\
\hline & $\%$ do total & $5,8 \%$ & $13,3 \%$ & $19,2 \%$ \\
\hline \multirow{4}{*}{$36-45$} & Frequência & 10 & 18 & 28 \\
\hline & $\%$ sexo & $35,7 \%$ & $64,3 \%$ & $100,0 \%$ \\
\hline & \% Importância & $24,4 \%$ & $22,8 \%$ & $23,3 \%$ \\
\hline & $\%$ do total & $8,3 \%$ & $15,0 \%$ & $23,3 \%$ \\
\hline \multirow{4}{*}{$46-50$} & Frequência & 7 & 10 & 17 \\
\hline & $\%$ sexo & $41,2 \%$ & $58,8 \%$ & $100,0 \%$ \\
\hline & \% Importância & $17,1 \%$ & $12,7 \%$ & $14,2 \%$ \\
\hline & $\%$ do total & $5,8 \%$ & $8,3 \%$ & $14,2 \%$ \\
\hline \multirow{4}{*}{$>50$} & Frequência & 2 & 5 & 7 \\
\hline & $\%$ sexo & $28,6 \%$ & $71,4 \%$ & $100,0 \%$ \\
\hline & \% Importância & $4,9 \%$ & $6,3 \%$ & $5,8 \%$ \\
\hline & $\%$ do total & $1,7 \%$ & $4,2 \%$ & $5,8 \%$ \\
\hline \multirow{4}{*}{ Total } & Frequência & 41 & 79 & 120 \\
\hline & $\%$ sexo & $34,2 \%$ & $65,8 \%$ & $100,0 \%$ \\
\hline & \% Importância & $100,0 \%$ & $100,0 \%$ & $100,0 \%$ \\
\hline & $\%$ do total & $34,2 \%$ & $65,8 \%$ & $100,0 \%$ \\
\hline
\end{tabular}

Fonte: Inquéritos, SPSS 


\section{Gráfico 9: Importância atribuída ao artesanato e idade}

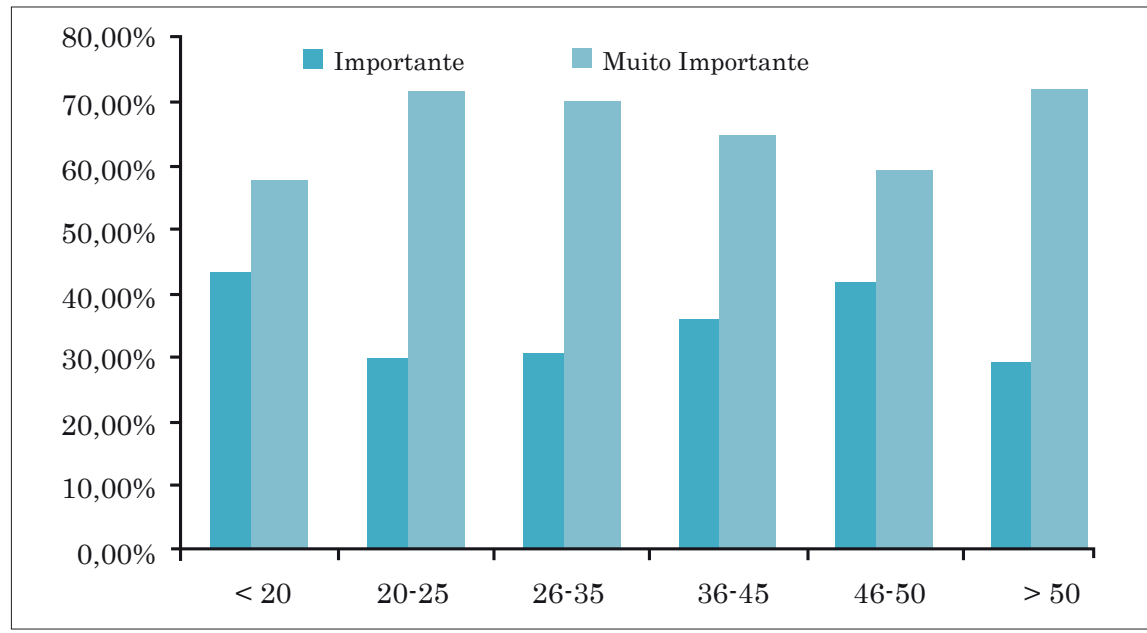

Fonte: Inquéritos, SPSS

A análise estatística envolveu estatísticas descritivas, frequências absolutas e relativas, e análise inferencial. Nesta, para testar a significância das diferenças entre as variáveis utilizou-se como referência para aceitar ou rejeitar a hipótese nula um nível de significância $(\alpha) \leq 0,05$. Como estamos a testar a independência entre variáveis de tipo qualitativo utilizou-se o teste do Qui-quadrado. Nas situações em que a tabela de contingência é de tipo 2 × $2(\mathrm{gl}=1)$ usou-se o teste exato de Fisher. O pressuposto do Qui-quadrado de que não deve haver mais do que 20,0\% das células com frequências esperadas inferiores a 5 foi analisado. Nas situações em que este pressuposto não estava satisfeito usou-se o teste do Qui-quadrado por simulação de Monte Carlo. As diferenças foram analisadas com o apoio dos resíduos ajustados estandardizados.

\section{Conclusão}

Com a consolidação do turismo enquanto atividade progressivamente fundamental, verificou-se que é preciso criar as condições adequadas para enfrentar as novas necessidades dos turistas. Tal como estipulado pelas entidades oficias cabo-verdianas, é importante garantir (i) um turismo sustentável e de alto valor acrescentado, com o envolvimento das comunidades locais no processo produtivo e nos seus benefícios; (ii) um turismo que maximize os efeitos multiplicadores, em termos de geração de rendimento, emprego e inclusão social; (iii) um turismo que aumente o nível de competitividade de Cabo Verde, através da aposta na qualidade dos serviços prestados e (iv) um turismo que promova Cabo Verde no mercado internacional como destino diversificado e de qualidade.

Para que isto seja alcançado, o turismo cultural a par do artesanato surgem como um complemento fundamental da atual oferta turística.

Toda a investigação e análise desenvolvida ao longo do presente artigo permitiram compreender que o turismo cultural da ilha de Santiago, tendo como foco o artesanato permite preservar o saber tradicional, como um elemento cultural cada vez mais importante para o Turismo pelo potencial de contribuição para o desenvolvimento local.

Como se referiu anteriormente, pretende-se com este trabalho analisar a preservação do artesanato enquanto valor cultural no contexto do fenómeno turístico na ilha de Santiago.

Da análise realizada ao longo do trabalho, chegou-se à conclusão que a ilha de Santiago é muito rica culturalmente, onde podemos encontrar por toda a ilha um vasto património cultural seja ela material e imaterial. No caso concreto do artesanato, verificámos a existência de uma grande diversidade de peças originais e diferenciadas.

A cultura é o ponto que diferencia um grupo de outro, é através deste que o grupo cria a sua identidade coletiva e conta a sua história. 
Preservar e conservar essa identidade é algo que enriquece as comunidades, é turisticamente rentável e os une socialmente, como um compromisso para o próprio bem comum que lhes dá sentido e reforça o sentimento de pertença.

Através dos resultados obtidos pelo trabalho realizado no terreno pode-se verificar que relativamente à importância da preservação do artesanato todos responderam positivamente, tendo esta variado entre importante e muito importante (respetivamente $34,2 \%$ e $65,8 \%$ ) o que demonstra que os artesãos e os habitantes estão conscientes da importância da preservação e conservação desse bem cultural.

Os homens são os que mais compram as peças artesanais, muito embora a diferença neste sentido em relação às mulheres não seja estatisticamente significativa. Por outro lado, os inquiridos mais jovens são os que afirmam que menos ou nunca compram.

Este estudo permitiu compreender o quão cientes estão os santiaguenses sobre a importância da valorização e da preservação da tradição, garantindo assim a transmissão geracional.

Por outro lado, identificaram-se algumas causas da decadência do artesanato e a forma como se tem tentado virar a situação através da criação de novos produtos, como os industriais que substituíram o barro ou artesanatos em fibras das plantas o que provocou mudanças na produção dando origem a novas exigências.

O futuro do artesanato encontra-se nas novas formas ou na inovação dos meios de divulgação e apresentação do mesmo.

Entre a cultura e o turismo existe uma relação reciprocidade sendo fundamental garantir o desenvolvimento harmonioso em benefício de ambos.

\section{Bibliografia}

Alberti, G. \& Giusti, D.

2012. Cultural, heritage, tourism and regional competitiveness. The Motor Valley Cluster. 3: 261-273. Băltescu, C. A. \& Boşcor, C.

2013. An analysis of the cultural tourism development in Romania, Bulletin of the Transilvania, University of Braşov. Vol. 6(55), No. 2: 115-120.

Bandarin, F.; Hosagrahar, J. et al.

2011. Why development needs culture. Journal of Cultural Heritage Management and Sustainable Development. 1(1): 15-25.

Belhassen, Y.; Caton, K. et al.

2008. The search for authenticity in the pilgrim experience. Annals of Tourism Research. 35(3): 668-689.

Boix, R.; Lazzaretti, L. et al

2012. The geography of creative industries in Europe. Comparing France, Great Britain, Italy and

Spain. Creative industries and innovation in Europe. Concepts, measures and comparatives case studies, Lazzeretti, L. (Ed.), Routledge, pp. 23-44.

Breda, Juan Gabriel; Meleddu, Marta \& Paulina, Manuela

2013. The Economic Impacts of Cultural Tourism. The Routledge Handbook of Cultural Tourism, pp. 110-115.

Butler, R.

2015. The evolution of tourism and tourism research, Tourism Recreation Research, 40: 16-27

Carvalho, Karoliny

2008. Turismo e Preservação do Património Cultural nos Espaços de Vida e Lazer dos Moradores do

Bairro da Praia Grande - São Luís. Revista de Ciências Humanas. 6(2).

Cohen, E.; Olsen, Kjell \& Pearce, Philip

2012. The Dilemma of Authenticity and Inauthenticity. Critical Debates in Tourism, ed. Tej Vir Singh, pp. 249-261.

Costa I.

2011. O Marketing Turístico Sustentável na Perspectiva das Comunidades Locais: o pólo de desenvolvimento turístico da serra da estrela, Portugal.

Dias, I.

2010. Turismo Cultural e Religioso no Distrito de Coimbra: Mosteiros e Conventos: Viagem entre o Sagrado e Profano; Universidade de Coimbra, Portugal

Emekli, G. \& Baykal, F.

2011. Opportunities of utilizing natural and cultural resources of Bornova (Izmir) through tourism. Procedia - Social and Behavioral Sciences. 19: 181-189. 
Fatemeh, Shafaei; Farzaneh, Mola \& Badaruddin, Mohamed

2015. Impact of Historical-Cultural Tourism on Sustaining Community Tourism: The Case of Kerman, Iran. Asian Social Science. 11(15): 187-196.

Figini, P. \& Vici, L.

2012. Off-season tourists and the cultural offer of a mass-tourism destination: The case of Rimini.

Tourism Management. 33: 825-839.

Fillis, I.

2009. Entrepreneurial crafts and the tourism industry. In: Tourism and entrepreneurship: International perspectives, Ateljevic, J., Page, S.: (eds.). Oxford: Butterworth-Heinemann.

Freeman, C.

2010. Cadeia Produtiva da Economia do Artesanato: desafio para o seu desenvolvimento sustentável; Ed. E - livre; Brasil.

Frey, S. \& Pamini, P.

2009. Making World Heritage Truly Global: The Culture Certificate Scheme. CESifo working paper. No.2745.

Girard, F. \& Nijkamp, P.

2009. Cultural Tourism and Sustainable Local Development. Surrey: Ashgate Publishing Limited.

$\mathrm{Hu}$, B. \& Yu, H.

2007. Segmentation by craft selection criteria and shopping involvement. Tourism Management. 28: 1079-1092.

Ielenicz, M. \& Simoni, S.

2013. The tourism system - main directions in evaluating its operation. Rev. Roum. Géogr. / Rom. Journ. Geogr., 571): 25-31.

INE

2018. Evolução e estatísticas do turismo por ilhas, 1999 a 2017. Cabo Verde: Instituto Nacional de Estatística.

Iorio, M. \& Wall, G.

2012. Behind the masks: Tourism and community in Sardinia. Tourism Management. 33: 1440-1449.

Istoc, Elena-Manuela

2012. Urban cultural tourism and sustainable development. International Journal for Responsible Tourism. 1(1): 38-56.

Jakulin, T. J.

2016. Systems approach for contemporary complex tourism systems, International Journal for Quality Research. 10(3): 511-522.

Kim, H. \& Jamal, T.

2007. Touristic quest for existential authenticity. Annals of Tourism Research. 34(1): 181-210.

Korunovski, S. \& Marinoski, N.

2012. Cultural tourism in Ohrid as a selective form of tourism development. Procedia - Social and Behavioral Sciences. 44: 104-113.

Lazano-Oyola, M.; Blancas et al.

2012. Sustainable tourism indicators as planning tools in cultural destinations. Ecological Indicators. 18: 659-675.

Lee,S-H.; Choi, J-Y. et al.

2013. Evaluating special centrality for integrated tourism management in rural areas using GIS and network analysis. Tourism Management. 34: 14-24.

Livramento, L.

2012. Turismo Cultural e Eventos: A Importância de Transformar os Eventos Culturais da Ilha de São Vicente em Produtos Turísticos; ISCEE Cabo Verde.

Lynch, F.; Duinker, N. et al.

2011. The demand for Mi'kmaw cultural tourism: Tourist perspectives. Tourism Management. 32: 977-986.

Madar, A.; Neacşu, A. et al.

2006. Calitatea serviciilor - premisa protecţiei consumatorilor. Braşov: Editura Universităţii Transilvania din Braşov.

Mbaiwa, E.

2011. Changes on traditional livelihood activities and lifestyles caused ba tourism development in the Okavango Delta, Botswana. Tourism Management. 32: 1050-1060. 
McLennan, C., Ruhanen, L., Ritchie, B. and Pham, T.

2012. Dynamics of Destination Development Investigating the Application of Transformation Theory. Journal of Hospitality \& Tourism Research. 36(2): 164-190.

Monteiro B.

2006. Protecção e Conservação do Artesanato ao Nivel Concelhio: O Caso de Vila Nova de Gaia; Universidade de Aveiro, Portugal.

Naidu, S.; Chand, A. \& Southgate, P.

2014. Determinants of innovation in the handicraft industry of Fiji and Tonga: an empirical analysis from a tourism perspective. Journal of Enterprising Communities: People and Places in the Global Economy. 8(4):318-330.

Ning, C. \& Hoon, D.

2011. Sustainable development strategy of tourism resources offered by regional advantage: Exploring the feasibility of developing an exotic "culture" resource for Weihai city of China. Procedia Engineering. 21: 543-552.

Okhrimenko, A.

2017. Strategic vectors of transformational shifts in the national tourism system of Ukraine. CES Working Papers. 9(3): 506-528.

Olsen, M.

2003. Tourism themed routes: A Queensland perspective. Journal of Vacation Marketing. 9(4): 331.341.

Panasiuk, A.

2013. European Union funds in the development of regional sustainable tourism economy in 2007-2013.

Tourism in Southern and Eastern Europe. pp. 267-277.

Pérez, Xerardo

2009. Turismo Cultural. Uma visão antropológica, Colección Pasos. Revista de Turismo y Património Cultural. 2: 63-75.

Raabova, Tereza; Merta; Petr \& Ticha, Alena

2013. Potential Methods for Measuring the Economic Impacts of Cultural Tourism. Routledge Handbook of Cultural Tourism, ed. Melanie Smith and Greg Richards, pp. 100-109. New York: Routledge.

Richards, G. \& Munsters, W.

(2010). Cultural Tourism Research Methods. Wallingford. CAB International.

Richards, G.

2011. Creativity and Tourism. The State of Art. Annals of Tourism Research. 38(4): 1225-1253.

Sarmento, E. M.

2008. O Turismo Sustentável como factor de desenvolvimento das pequenas economias insulares: o caso de Cabo Verde; Edições Universitárias Lusófonas.

Savushkin, D.

2014. Features and patterns of transformation economy in the market environment. Bulletin of Berdyansk University of Management and Business. 2(26): 49-54.

Tao, H. \& Wall, G.

2009. Tourism as a sustainable livelihood strategy. Tourism Management. 30: 90-98.

UNESCO

2009. Investir na Diversidade Cultural e no Dialogo Intercultural.

WTTC [World Travel \& Tourism Council]

2018. Travel \& Tourism Economic Impacts 2015: Cape Verde. WTTC.

Yang, J.; Ryan, C. et al.

2013. Social conflict in communities impacted by tourism. Tourism Management. 35: 82-93.

Zeng, B. \& Ryan, C.

2012. Assisting the poor in China through tourism development: A review of research. Tourism Management. 3: 230-248.

\section{Notas}

Antigamente utilizava-se essencialmente o barro nas construções das casas.

Recibido:

$11 / 07 / 2018$

Reenviado:

$25 / 09 / 2018$

Aceptado:

$02 / 08 / 2018$

Sometido a evaluación por pares anónimos 